\title{
Congenital supravalvar mitral ring: An underestimated anomaly
}

\author{
Alessandra Toscano, MD, PhD, ${ }^{\mathrm{a}}$ Luciano Pasquini, MD, FESC, ${ }^{\mathrm{a}}$ Roberta Iacobelli, MD, ${ }^{\mathrm{a}}$ Roberto M. Di Donato, MD, ${ }^{\mathrm{b}, *}$ \\ Francesca Raimondi, MD, ${ }^{\mathrm{a}}$ Adriano Carotti, MD, ${ }^{\mathrm{b}}$ Vincenzo Di Ciommo, MD, ${ }^{\mathrm{c}}$ and Stephen P. Sanders, MD, FACC
}

\begin{abstract}
Objective: Congenital mitral ring is a rare subtype of congenital mitral stenosis. Our objective is to review the anatomic findings and surgical results of this lesion and to identify early predictors of outcome.
\end{abstract}

\begin{abstract}
Methods: Clinical reports, echocardiographic studies, cardiac catheterizations, surgical reports, and follow-up data of all patients with mitral ring diagnosed at the Bambino Gesù Hospital were retrospectively reviewed.
\end{abstract}

Results: Between January of 1987 and June of 2007, a mitral ring was diagnosed in 25 patients (13 male) with a mean age at diagnosis of 36 months. The ring was identified in a single neonate but seemed to develop and progress during infancy. All but 1 patient had associated cardiac anomalies. We identified 2 distinct subtypes: "intramitral ring" in 18 of 25 patients $(72 \%)$, associated with complex valve pathology and a worse outcome, and "supramitral ring" in 7 of 25 patients $(18 \%)$, in whom the mitral apparatus was usually normal and the outcome was better. The ring was surgically removed in 13 of 25 patients $(52 \%$ ) (mean Doppler gradient $15 \pm 4 \mathrm{~mm} \mathrm{Hg}$ ). The gradient decreased in 9 of 13 patients (mean diastolic transmitral gradient $\leq 5 \mathrm{~mm} \mathrm{Hg}$ ) and has remained stable during a mean follow-up of 90 months. The mean diastolic gradient remained high $(>8 \mathrm{~mm} \mathrm{Hg})$ in the other 4 patients, all with intramitral ring. All 4 patients underwent repeat mitral valvuloplasty. There were no operative or late deaths.

Conclusion: Two types of congenital mitral ring, with diverse valve pathology and outcome, were identified. Rarely seen in neonates, the ring develops and often progresses during infancy. Recognition is important because surgical results are better than for other forms of congenital mitral stenosis.

Video clip is available online.

Mitral ring is a subtype of congenital mitral stenosis. ${ }^{1}$ Its morphology ranges from a thin membrane to a thick discrete fibrous ridge partially or completely encircling the mitral orifice and frequently adhering to the mitral leaflets. Occasionally isolated, ${ }^{2}$ mitral ring is more often associated with other leftsided obstructive lesions (Shöne complex). ${ }^{3}$ The variability of the mitral valve pathology and the associated defects hamper attempts at identifying optimal management strategies. Our objective was to review the anatomic findings and surgical results of mitral ring and to identify early predictors of outcome.

\section{MATERIALS AND METHODS \\ Patients}

We searched the files of the echocardiography laboratory and the surgical database at Bambino Gesù Hospital to identify all patients in whom

From the Departments of Cardiology ${ }^{\mathrm{a}}$ and Cardiothoracic Surgery, ${ }^{\mathrm{b}}$ Bambino Gesù Pediatric Hospital, Rome, Italy; and UO Epidemiology, ${ }^{\mathrm{c}}$ Bambino Gesù Hospital, Rome, Italy.

* American Association for Thoracic Surgery member.

Received for publication Feb 14, 2008; revisions received July 2, 2008; accepted for publication Aug 11, 2008.

Address for reprints: Luciano Pasquini, MD, FESC, Department of Cardiology and Cardiothoracic Surgery, Bambino Gesù Hospital, Piazza S. Onofrio 400165 ,

Rome, Italy (E-mail: pasquini@opbg.net).

J Thorac Cardiovasc Surg 2009; 137:538-42

$0022-5223 / \$ 36.00$

Copyright (c) 2009 by The American Association for Thoracic Surgery

doi:10.1016/j.jtcvs.2008.08.023

mitral ring was diagnosed between 1987 and 2007. Patients with hypoplastic left-sided heart syndrome and atrioventricular discordance were excluded.

\section{Data Collection}

Fetal or postnatal echocardiograms, preoperative evaluations, operative reports, inpatient charts, outpatient follow-up visits, and cardiac catheterizations of all patients with congenital mitral ring were retrospectively reviewed. The initial transthoracic echocardiogram for each patient was reviewed by a single observer blinded to patients' outcomes. The subvalvular components, such as leaflet excursion, mitral valve chordal length, and mitral papillary muscle morphology (number, spacing, and dominance), were retrospectively analyzed. Reduced chordal length was present when little or no space was seen between the free edge of the leaflet and the head of the papillary muscle. The interpapillary muscle distance was considered reduced when the bases of the papillary muscles were touching or nearly so. Mitral valve anomalies were defined according to the classification of Ruckman and Van Praagh. ${ }^{4}$ Quantitative variables analyzed included the mitral valve annular dimension and $z$ score, and mitral valve inflow Doppler mean and peak gradients. A mean diastolic gradient of $8 \mathrm{~mm} \mathrm{Hg}$ or more across the mitral apparatus was considered significant. Peak velocity of the tricuspid regurgitant jet was measured to calculate systolic right ventricular pressure. Associated defects were methodically sought.

Cardiac catheterization data were reviewed, and the mean diastolic transmitral gradient and pulmonary artery pressure were recorded. Angiograms were reviewed for other heart defects. A favorable outcome was defined as lack of progression of the stenosis during follow-up greater than a mean diastolic gradient of $8 \mathrm{~mm} \mathrm{Hg}$ or a postoperative mean diastolic gradient of $5 \mathrm{~mm} \mathrm{Hg}$ or less.

\section{Statistical Analysis}

The Statistical Package for the Social Sciences (SPSS Inc, Chicago, Ill) for Windows version 13 was used for data analysis. Risk factors for recurrent mitral stenosis and reoperation were assessed by univariate analysis. The Student $t$ test was used for continuous variables, and the chi-square test was used for dichotomous variables. 


\section{Abbreviation and Acronym}

NYHA $=$ New York Heart Association

\section{RESULTS}

\section{Diagnosis and Clinical Course}

Congenital mitral ring was diagnosed in 25 patients (13 male) between January of 1987 and June of 2007. Nine patients had a fetal echocardiogram showing aortic coarctation with mild-to-moderate left ventricular hypoplasia. The median age was 21 months (range 0-218 months) at initial diagnosis of mitral stenosis and 36 months (range 0-248 months) at subsequent recognition of the mitral ring. Mitral ring was diagnosed in a single neonate. Mitral stenosis was progressive in most patients $(72 \%)$. Nineteen patients $(76 \%)$ had previously undergone coarctation repair.

\section{Anatomic Types of Mitral Ring}

Two types of congenital mitral ring were identified: "supramitral" in 7 patients and "intramitral" in 18 patients.

The "supramitral" ring was a fibrous, shelf-like membrane just above the mitral annulus, not adhering to valve leaflets and associated with a normal subvalvar apparatus (Figure 1, Videoclip 1). It differed from cor triatriatum sinister for its attachment between the opening of the atrial appendage and the mitral annulus.

The "intramitral" ring was a thin membrane within the mitral tunnel, closely adherent to the valve leaflets (Figure 2, Videoclip 2a-2b). It consistently impaired valve leaflet motion and was combined with Shone complex and abnormal subvalvular apparatus. The mitral abnormalities associated with intramitral ring included hypomobility of the posterior leaflet $(n=13)$, reduced chordal length $(n=12)$, reduced interpapillary muscle distance $(\mathrm{n}=12)$, hypoplastic mitral annulus ( $z$ score $<-2, \mathrm{n}=13$ ), and a dominant papillary muscle ( $\mathrm{n}=8,5$ anterolateral, 3 posteromedial).

\section{Associated Defects}

Shone complex was diagnosed in 20 of 25 patients. In 4 of 25 patients, other associated defects included tetralogy of Fallot $(\mathrm{n}=1)$, perimembranous ventricular septal defect $(\mathrm{n}=2)$, and inlet muscular ventricular septal defect $(\mathrm{n}=$ 1). The remaining patient had an isolated supravalvar mitral ring diagnosed at 3 years of age. A bicuspid aortic valve was noted in 15 of 25 patients $(60 \%)$, a ventricular septal defect was noted in 8 of 25 patients $(32 \%)$, and a persistent left superior vena cava draining into the coronary sinus was noted in 7 of 25 patients $(28 \%)$.

In the group with Shone complex, diffuse aortic arch hypoplasia was present in 16 of 20 patients. Valvar aortic stenosis developed in 3 of 20 patients, subvalvar aortic stenosis developed in 8 of 20 patients ( 6 discrete subvalvar membrane, 2 fibromuscular tunnel), and supravalvar aortic stenosis developed in 1 of 20 patients. A ventricular septal defect was present in 5 of 20 patients, and a secundum atrial septal defect was present in 6 of 20 patients. The mitral valve was mildly or moderately hypoplastic at birth ( $z$ score of mitral anulus $<$ $-2)$ in 10 of 20 patients. Noncardiac anomalies were noted in 7 of 25 patients $(32 \%)$ : pyloric stenosis $(n=2)$, hydrocephalus $(n=1)$, choroid plexus cyst $(n=1)$, cleft lip and palate $(\mathrm{n}=1)$, web neck $(\mathrm{n}=1)$, and lax ligaments $(\mathrm{n}=1)$.

\section{Surgical Treatment}

Thirteen patients underwent surgery for congenital mitral ring (Table 1). Indications included growth failure (less than

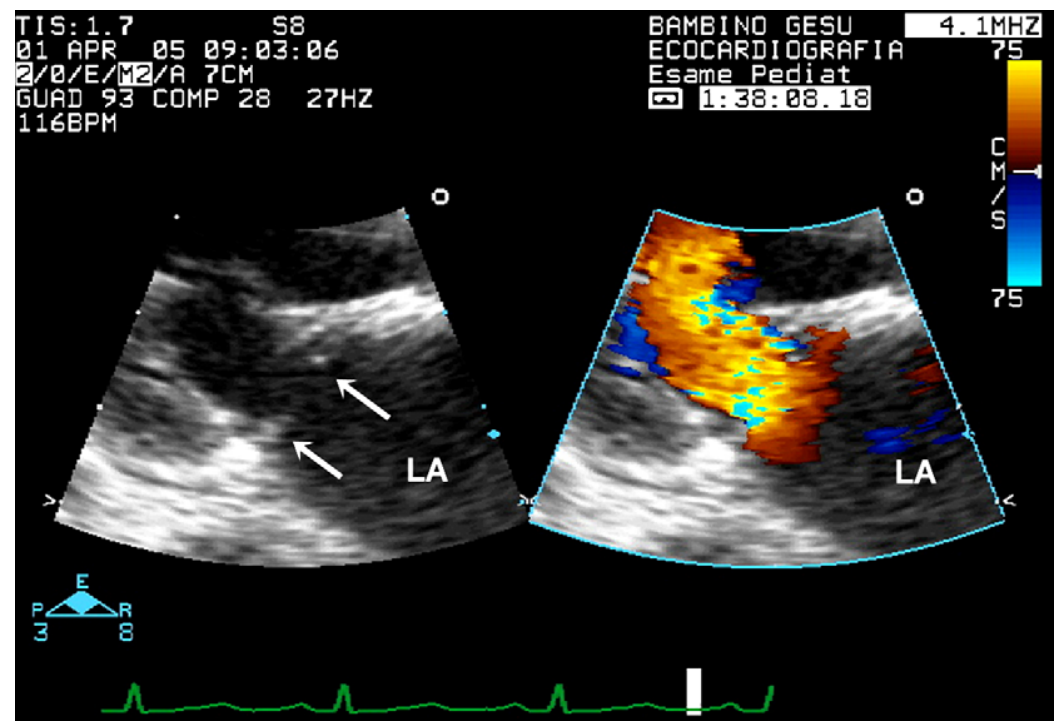

FIGURE 1. Right Panel: Supramitral stenosis showing the flow disturbance above the annulus of mitral valve. Left Panel: Echocardiographic view of supramitral ring (arrows) in diastole from parasternal long-axis view. LA, Left atrium. 


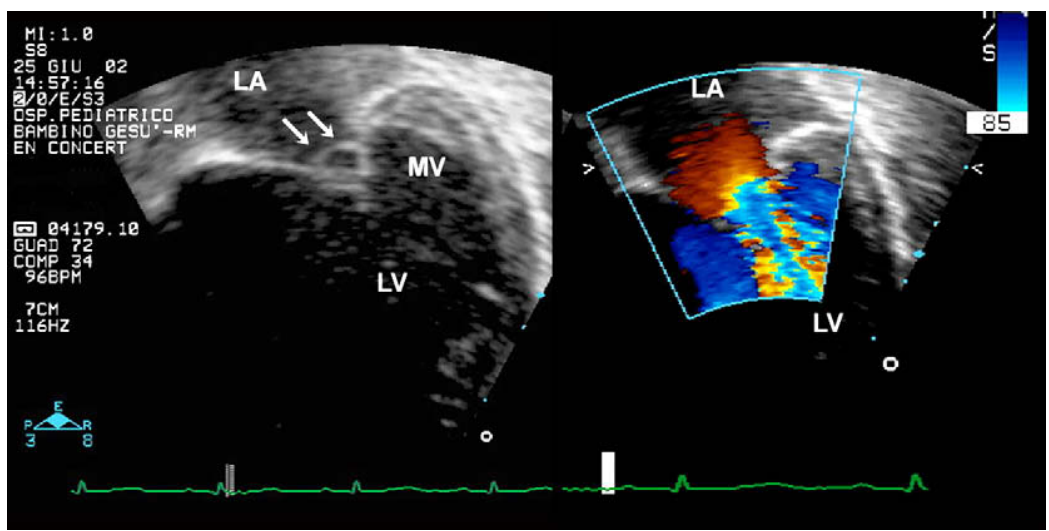

FIGURE 2. Echocardiographic view of intramitral ring: circumferential ridge (arrows) adherent to the mitral valve leaflets in diastole. $L A$, Left atrium; $L V$, left ventricle; $M V$, mitral valve.

the fifth percentile), intractable congestive heart failure, or systemic right ventricular pressure. ${ }^{5,6}$ At the time of operation, 3 patients were in New York Heart Association (NYHA) class I, 6 patients were in NYHA class II, 3 patients were in NYHA class III, and 1 patient was in NYHA class IV. The median age at surgery was 55 months (range 6251 months). In the 5 patients who underwent cardiac catheterization, systolic and mean pulmonary artery pressure were $60 \pm 10 \mathrm{~mm} \mathrm{Hg}$ and $20 \pm 7 \mathrm{~mm} \mathrm{Hg}$, respectively. Percutaneous transcatheter balloon dilation was not attempted in any patient..$^{5}$

In all 13 patients, surgical inspection confirmed the preoperative diagnosis, particularly in regard to the supra- or intramitral location of the ring. Surgery consisted of simple resection of a "supramitral" ring in 5 of 13 patients. In all 8 patients with "intramitral" ring, the surgeon found that the obstructing feature was a true ring and not simply a growth of fibrous tissue onto the leaflets (as possibly seen in the case of concomitant endocardial fibroelastosis). In these cases, the tissue was also peeled off the mitral leaflets. In 2 of these 8 cases, fused, short chordae were treated by fenestration and splitting of the papillary muscle (Table 1). Additional procedures performed included ventricular septal defect closure in 5 patients (in 1 patient at the time of coarctectomy), resection of subaortic membrane in 1 patient, Ross operation in 2 patients, and tetralogy of Fallot repair in 1 patient. There were

TABLE 1. Comparison of outcomes in patients with intramitral ring versus supramitral ring

\begin{tabular}{lcclc}
\hline & $\begin{array}{c}\text { No. of } \\
\text { patients }\end{array}$ & Intervention & \multicolumn{1}{c}{$\begin{array}{c}\text { Type of } \\
\text { surgery }\end{array}$} & $\begin{array}{c}\text { Good } \\
\text { resolution }\end{array}$ \\
\hline SMR type & 7 & 5 & Simple resection & $5(100 \%)$ \\
IMR type & 18 & 8 & $\begin{array}{c}\text { Fibrous peeling } \\
\pm \text { fenestration } \\
\text { and splitting of }\end{array}$ & $4(50 \%)$ \\
& & & papillary muscle & \\
& & & & \\
& Total 25 & 13 & & \\
\hline
\end{tabular}

SMR, Supramitral ring; IMR, intramitral ring. no operative or late deaths. Nine patients (5 with supramitral ring and 4 with intramitral ring) had good resolution of mitral stenosis (mean diastolic transmitral gradient $\leq 5 \mathrm{~mm} \mathrm{Hg}$ ) and have remained stable during a mean follow-up period of 90 months (range 3 months to 19 years) (Table 2). Four patients, all with Shone complex and intramitral ring, had inadequate relief of mitral stenosis (mean diastolic transmitral gradient $\geq 8 \mathrm{~mm} \mathrm{Hg}$ ), mainly caused by an obstructive subvalvar apparatus (Table 3), and underwent a secondary mitral valvuloplasty with splitting of the papillary muscles. The median time interval between initial repair and reoperation was 21.5 months (range 13-28 months); in none of these patients was additional resection of residual ring tissue required. In this group of patients who underwent a second operation at a mean follow-up of 49 months, the mean gradient was 8.5 $\pm 1.5 \mathrm{~mm} \mathrm{Hg}$. Mild mitral insufficiency was present in 4 patients after surgery. By univariate analysis, predictive factors for residual mitral stenosis were mitral valve hypoplasia and an abnormal tensor apparatus $(P<.05)$ (Table 3$)$.

TABLE 2. Outcomes in patients with supramitral ring versus intramitral ring

\begin{tabular}{ll}
\hline SMR type & Preoperative transmitral gradient $14 \mathrm{~mm} \mathrm{Hg}$, range \\
& $12-15 \mathrm{~mm} \mathrm{Hg}$ \\
& Mitral surgical repair $5 / 7(71 \%)$ \\
& Postsurgical outcome \\
& Need for reoperation none $(100 \%)$ \\
& Late follow-up median transmitral gradient $\leq 4 \mathrm{~mm} \mathrm{Hg}$ \\
& Late follow-up right ventricular pressure $\leq 30 \mathrm{~mm} \mathrm{Hg}$ \\
IMR type & Mitral surgical repair $8 / 18(44 \%)$ \\
& Postsurgical outcome \\
& Need for reoperation $4 / 8(50 \%)$ \\
& Interval between the first and second operation $21.5 \mathrm{mo}$, \\
& range $13-28$ mo \\
& Late follow-up median gradient $14 / 18 \leq 5 \mathrm{~mm} \mathrm{Hg}$ \\
& $4 / 1813 \mathrm{~mm} \mathrm{Hg}$, range $8-15 \mathrm{~mm} \mathrm{Hg}$ (follow-up $49 \mathrm{mo})$ \\
& Late follow-up right ventricular pressure $14 / 18 \leq 30 \mathrm{~mm} \mathrm{Hg}$ \\
& $4 / 1855 \mathrm{~mm} \mathrm{Hg}$, range $50-60 \mathrm{~mm} \mathrm{Hg}$ \\
\hline
\end{tabular}


TABLE 3. Morphologic features in 4 patients with intramitral ring type undergoing reoperation

\begin{tabular}{|c|c|c|c|c|c|}
\hline $\begin{array}{c}\text { No. of } \\
\text { patients }\end{array}$ & $\begin{array}{c}\text { Abnormal } \\
\text { tensor } \\
\text { apparatus }\end{array}$ & $\begin{array}{l}\text { Mitral valve } \\
\text { morphology }\end{array}$ & CoAo & BAV & $\begin{array}{c}\text { Subaortic } \\
\text { obstruction }\end{array}$ \\
\hline 1 & Yes & $\begin{array}{l}\text { Mitral valve hypoplasia } \\
\text { Hypomobility posterior } \\
\text { leaflet } \\
\text { Reduced chordal length }\end{array}$ & Yes & Yes & Yes \\
\hline 2 & Yes & $\begin{array}{l}\text { Mitral valve hypoplasia } \\
\text { Hypomobility posterior } \\
\text { leaflet } \\
\text { Reduced chordal length } \\
\text { Reduced interpapillary } \\
\text { muscle distance }\end{array}$ & Yes & Yes & No \\
\hline 3 & Yes & $\begin{array}{l}\text { Mitral valve hypoplasia } \\
\text { Hypomobility posterior } \\
\text { leaflet } \\
\text { Reduced interpapillary } \\
\text { muscle distance }\end{array}$ & Yes & No & Yes \\
\hline 4 & Yes & $\begin{array}{l}\text { Reduced chordal length } \\
\text { Reduced interpapillary } \\
\text { muscle distance }\end{array}$ & Yes & Yes & Yes \\
\hline
\end{tabular}

\section{DISCUSSION}

Review of our series of mitral ring has disclosed that there are actually 2 types of mitral ring: "supramitral" and "intramitral." The mitral valve pathology associated with these 2 types of ring differs, as does the response to surgery. "Supramitral" ring is usually associated a normal mitral valvar apparatus and can occur with various congenital heart defects. $^{7-11}$ "Intramitral" ring was always combined with Shone complex in our series, and the subvalvular apparatus was abnormal. Therefore, we suggest that the "intramitral" type belongs to the broader category of congenital mitral stenosis with different degrees of obstruction both at the level of the ring and at the level of the subvalvar apparatus. A supravalvar ring has also been described above an otherwise normal tricuspid valve in a patient with congenitally corrected transposition of the great arteries and atrioventricular discordance. ${ }^{12}$ This finding, plus the dissimilar mitral anatomy, suggests that the 2 types of congenital mitral ring might have different embryologic origins. The supravalvar type could represent a form of left atrial outlet obstruction, whereas the intravalvar type could be part of an intrinsic mitral valve pathology. Congenital mitral ring was never seen in the fetus and only rarely seen in the neonate. It seems to appear during early infancy, often associated with rapidly developing mitral stenosis. This could suggest either postnatal ring development or difficult visualization of a thin structure in the neonate. Most of our patients initially presented with aortic coarctation (combined with aortic arch hypoplasia in $\sim 60 \%$ of the cases). The associated intracardiac lesions and the diagnosis of the Shone complex were usually appar- ent after the neonatal period. The "supramitral ring" was easier to identify because it is clearly discernible from the mitral valve leaflets. Although excision of a "supramitral" ring is straightforward and definitive, surgery of "intramitral" ring is more challenging. Ring resection, although mandatory, is rarely sufficient, because the anatomy of subvalvular apparatus also contributes significantly to inflow obstruction. Satisfactory hemodynamic results were achieved by splitting the papillary muscles and opening the obliterated interchordal spaces to increase the effective mitral orifice. In this variant, commissurotomy with separation of the chordae may postpone or avoid valve replacement. ${ }^{13-15}$ Previous studies suggested that late outcomes are excellent, and the need for reintervention is uncommon. ${ }^{5,16-18}$ Our operative experience with congenital mitral ring compares favorably with other series. ${ }^{16-19}$ Furthermore, the mitral ring did not recur after surgery. In all of the cases of "supramitral" and in half of the cases of "intramitral" obstruction, ring resection led to excellent long-term results (Table 1). In the remaining $50 \%$ of the patients in the "intramitral" group, there was residual stenosis. The latter was always secondary to an abnormal subvalvar apparatus or valve hypoplasia, because it was already evident at the first operation and, despite a second intervention, remained moderate to severe at mid-term follow-up (Tables 1-3). Predictors of poor surgical outcome were mitral annulus hypoplasia at birth and anomalous subvalvar apparatus $(P<.05)$. Others reported that age less than 1 year was also associated with a poor surgical outcome, ${ }^{19}$ but our patient population is not large enough to confirm this observation. The prevalence of left ventricular outflow obstruction in our series was $49 \%$ for subvalvar obstruction and $26 \%$ for valvar obstruction. Subaortic stenosis was rarely present at birth and developed during the first years of life, becoming rapidly progressive in some cases. ${ }^{20,21} \mathrm{Re}-$ current subaortic stenosis after resection was observed in 3 patients with residual ring stenosis. A Ross-Konno procedure was used in 2 of these patients with diffuse tunnel subaortic stenosis to relieve the obstruction.

\section{CONCLUSIONS}

Congenital mitral ring can be supravalvar or intravalvar. Rarely seen at birth, mitral ring develops in infancy and can cause rapidly progressing mitral stenosis. Accurate diagnosis is important because surgical results are better than for other forms of congenital mitral stenosis, particularly when associated with normal underlying mitral valve anatomy.

\section{References}

1. Fisher T. Two cases of congenital heart disease of the left side of the heart. $\mathrm{Br} \mathrm{Med}$ J. 1902;1:639-41.

2. Chung KJ, Manning JA, Lipchik EO, Gramiak R, Mahoney EB. Isolated supravalvar stenosing ring of the left atrium: diagnosis before operation and successful surgical treatment. Chest. 1974;65:25-8.

3. Shone JD, Sellers RD, Anderson RC, Adams P, Lillehei CW, Edwards JE. The developmental complex of "parachute mitral valve," supravalvar ring to the 
left atrium, subaortic stenosis and coarctation of the aorta. Am J Cardiol. 1963;11: 714-25.

4. Ruckman RN, Van Praagh R. Anatomic types of congenital mitral stenosis: report of 49 autopsy cases with consideration of diagnosis and surgical implications. Am J Cardiol. 1978;42:592-601.

5. McElhinney DB, Sherwood MC, Keane JF, del Nido PJ, Almond CS, Lock JE. Current management of severe congenital mitral stenosis: outcomes of transcatheter and surgical therapy in 108 infants and children. Circulation. 2005;112: 707-14. Epub 2005 Jul 25.

6. Serraf A, Zoghby J, Belli E, Lacour-Gayet F, Aznag H, Houyel L, et al. Congenital mitral stenosis with or without associated defects: an evolving surgical strategy. Circulation. 2000;102(19 suppl. 3):III166-71.

7. Becker AE, Becker MJ, Edwards JE. Anomalies associated with coarctation of aorta; particular reference to infancy. Circulation. 1970;41:1067-75.

8. Anabtawi IN, Ellison RG. Congenital stenosing ring of the left atrioventricular canal (supravalvular mitral stenosis). J Thorac Cardiovasc Surg. 1965;45:994-1005.

9. Benrey J, Leachman RD, Cooley DA, Klima T, Lufschanowski R. Supravalvular mitral stenosis associated with tetralogy of Fallot. Am J Cardiol. 1976;37:111-4.

10. Cassano G. Congenital annular stenosis of the left atrioventricular canal. Am J Cardiol. 1964;13:708-11.

11. Chesler E, Beck W, Barnard CN, Schrire V. Supravalvular stenosing ring of the left atrium associated with corrected transposition of the great vessels. Am J Cardiol. 1973;31:84-8.

12. Marino B, Sanders SP, Parness IA, Colan SD. Obstruction of right ventricular inflow and outflow in corrected transposition of the great arteries (SLL): two dimensional echocardiographic diagnosis. J Am Coll Cardiol. 1986;8:407-11.
13. Brauner RA, Laks H, Drinkwater DC Jr, Scholl F, McCaffery S. Multiple left heart obstructions (Shone's anomaly) with mitral valve involvement: long-term surgical outcome. Ann Thorac Surg. 1997;64:721-9.

14. Coles JG, Williams WG, Watanabe T, Duncan KF, Sherret H, Dasmahapatra HK, et al. Surgical experience with reparative techniques in patients with congenital mitral valve anomalies. Circulation. 1987;76(3 Pt 2):III117-22.

15. Aharon AS, Laks H, Drinkwater DC, Chugh R, Gates RN, Grant PW, et al. Early and late results of mitral valve repair in children. J Thorac Cardiovasc Surg. 1994; 107:1262-70.

16. Sullivan ID, Robinson PJ, de Leva IM, Graham TP Jr. Membranous supravalvar mitral stenosis: a treatable form of congenital heart disease. J Am Coll Cardiol. 1986;8:159-64.

17. Collison SP, Kaushal SK, Dagar KS, Iyer PU, Girotra S, Radhakrishnan S, et al. Supramitral ring: good prognosis in a subset of patients with congenital mitral stenosis. Ann Thorac Surg. 2006;81:997-1001.

18. Moore P, Adatia I, Spevak PJ, Keane JF, Perry SB, Castaneda AR, et al. Severe congenital mitral stenosis in infants. Circulation. 1994;89:2099-106.

19. Tulloh RM, Bull C, Elliott MJ, Sullivan ID. Supravalvar mitral stenosis: risk factors for recurrence or death after resection. Br Heart J. 1995;73: 164-8.

20. Brown JW, Ruzmetov M, Vijay P, Hoyer MH, Girod D, Rodefeld MD, et al. Operative results and outcomes in children with Shone's anomaly. Ann Thorac Surg. 2005;79:1358-65.

21. Brown JW, Ruzmetov M, Vijay P, Rodefeld MD, Turrentine MW. Surgery for aortic stenosis in children: a 40-year experience. Ann Thorac Surg. 2003;76: $1398-411$. 